\title{
Efficiency investigation of SS and SP compensation topologies for wireless power transfer
}

\author{
Masood Rehman', Perumal Nallagownden ${ }^{2}$, Zuhairi Baharudin ${ }^{3}$ \\ 1,2,3 Electrical and Electronics Engineering Department, Universiti Teknologi PETRONAS \\ 32610 Bandar Seri Iskandar, Perak, Malaysia \\ ${ }^{3}$ SIRIM Berhad, No. 1 Persiaran Dato' Menteri, Section 2 P.O. Box 7035, 40700 Shah Alam, Malaysia
}

\begin{tabular}{l}
\hline \hline Article Info \\
\hline Article history: \\
Received Mar 11, 2019 \\
Revised May 28, 2019 \\
Accepted Jul 3, 2019 \\
\hline
\end{tabular}

Keywords:

Circular Coil

Efficiency Investigation

Series-Parallel (SP) Topology

Series-Series (SS) Topology

Unsymmetrical Coils

Wireless Power Transfer

\begin{abstract}
Wireless power transfer (WPT) using inductive and resonant coupling has been widely explored in recent years for ease and safety over conventional cable charging systems. The efficiency of WPT systems is reducing drastically due to an increase in air-gaps and misalignment between transmitter (Tx) and receiver (Rx). Many circuit topologies have been analyzed to improve the efficiency of WPT system based on symmetrical coils. However, the circuit topologies have not been studied widely for unsymmetrical coils. This paper presents the investigation of two fundamental topologies i.e. Series-Series (SS) and Series-Parallel (SP) for unsymmetrical coils as well as symmetrical coils. Theoretical analysis of both the compensation topologies have been accomplished, then modeling of both the topologies have been done using two different combination of circular coils. In first case, two similar size coils have been designed and in second case transmitter coil of higher dimensions than receiver coil is designed. The efficiency of the system has been analyzed at multiple distances in both cases by integrating coil structure with the circuit. The overall result show that when Tx is bigger than Rx, the SP topology gives better efficiency than SS counterpart.
\end{abstract}

Copyright $(\mathbb{C} 2019$ Institute of Advanced Engineering and Science. All rights reserved.

\section{Corresponding Author:}

Masood Rehman,

Electrical and Electronics Engineering Department,

Universiti Teknologi PETRONAS,

32610 Bandar Seri Iskandar, Perak, Malaysia

Email: masood.rehman_g03229@utp.edu.my

\section{INTRODUCTION}

Wireless power transfer (WPT) using inductive and resonant coupling has become one of the demanded technologies in recent years. WPT can be very useful for charging electric vehicles, electronic appliances and implantable medical devices. The idea of WPT was initially presented by Nikola Tesla in the late 19th Century [1]. WPT can be widely separated into two types; radiative or non-radiative [2, 3]. Note that because of unidirectional nature of radiative approach of WPT, it does not offer any good adjustment between the efficiency of WPT and its directionality [4]. The non-radiative WPT works on basis of inductive coupling and magnetic resonant coupling to transfer the energy from the transmitting coil to receiving coil. Usually, the self-resonance frequency of coils is achieved from parasitic capacitance and self-inductance of coils, however, the parasitic capacitances are inadequate for resonating both the coils according to estimated frequency, then a lumped capacitor can be included to make it operate on desired frequency $[5,6]$.

In year 2007, a technique of WPT using magnetic resonance coupling (MRC) was proposed by researchers at Massachusetts Institute of Technology (MIT). They used four self-resonant coils of $30 \mathrm{~cm}$ radius to light up a bulb of 60 Watts at $2 \mathrm{~m}$ distance with efficiency of $40 \%$ [8, 9]. Thereafter, the WPT technology was also commercialized for the charging of portable electronic components, such as mobile 
phones, tooth brushes etc. [7]. WPT technology using inductive and resonant coupling can be a good solution for charging of mobile phones in a room, charging of robot in future, charging of implantable medical devices etc. Nevertheless, WPT using inductive and resonant coupling possess advantages over other techniques at short and medium distances, but still this technology is ineffective because the variation in distance between the transmitter (Tx) and receiver $(\mathrm{Rx})$ causes the change in resonance frequency, thus affects the efficiency. Furthermore, the misalignment between the Tx and Rx can affect the power transfer efficiency [10,11]. Many research studies have been conducted to improve the efficiency. Study on the circuit model and frequency analysis are presented in [12,13]. The splitting frequency occurs, when single or multiple coils from primary and secondary side come in close vicinity to each other, then the production of strong relative magnetic field is inevitable, which can cause the split of frequency in two different peaks [14], which ultimately reduces the power transfer capability of WPT system. Many circuit topologies have been studied to improve the efficiency of WPT system. Analysis of secondary series and parallel topology for inductive power transfer for achieving optimal efficiency is carried out in [15] and load independent voltage transfer is discussed, however, unsymmetrical coils have not been utilized. Hybrid topologies for WPT are investigated for constant current and constant voltage output to charge the batteries in [16]. Modeling and $\eta$ $\alpha$-pareto optimization of WPT coils for electric vehicles using different topologies is conducted in [17]. A general theory focusing on SP-Combined topology is studied in [18] and equations of efficiency are derived. Analysis of WPT using SS and SP-Combined Topology is provided in [19, 20]. An optimization technique to enhance the efficiency of WPT system using SS topology is proposed in [21]. It was demonstrated that the maximum efficiency can be achieved when $\mathrm{Tx}$ and $\mathrm{Rx}$ are not on same plane and $\mathrm{Rx}$ has some misalignment with tilt angle of $\pi / 4$. In general, tilt angle affects the coupling coefficient; however, this paper does not discuss the overall impact of coupling coefficient on the efficiency of system. Finite Element Analysis is conducted by designing two E type ferrite cores with SS compensation and a meta material is placed near the transmitter side E type core to improve the transfer distance by enhancing electromagnetic induction [22], however to design E type Tx and Rx coils may not be feasible in many situations. Simulation of Multiple Coil Model for WPT System are carried out in [23]. In this model, 4 overlapped coils were used as a Tx coil and single coil was used as a receiver coil to obtain $15 \%$ more efficiency than just single Tx coil, but this type of model has increased capital cost. Simulation and Analysis of WPT system are conducted in [24], it was concluded that the changes in number of turns of coils and distance affects the overall efficiency of system.

This paper presents the investigation of two fundamental topologies i.e. Series-Series (SS) and Series-Parallel (SP) of inductive WPT system. Simulation is performed by designing the coil and integrating it with circuit structure to examine the overall performance of the model. Theoretical analysis of both the compensation topologies have been accomplished, then modeling of both the topologies have been done using two different combination of coils. In first case, two same size coils have been taken and in second case transmitter coil of higher dimensions than receiver coil is designed. The efficiency of the system has been analyzed at multiple distances in both cases. Second case coil combination can be suitable for biomedical applications, where receiver coil mostly remains smaller as compared to transmitter coil. This paper is organized in such a manner that the section 1 includes the Introduction. Section 2 comprises of the analysis and derivation of efficiency equation for WPT system. The design of circular coil and finite element analysis is provided in section 3. The simulation results of WPT model are given in section 4 and the conclusion is presented in section 5 .

\section{RESEARCH METHOD}

This section includes the efficiency analysis of Series-Series (SS) topology, Series-Parallel (SP) topology. The equations of efficiencies for both the circuit topologies have been derived in section 2.1 and section 2.2. The combination of symmetrical and unsymmetrical coils structures has been designed in section 2.3. The magnetic field at three different distances for both combinations is calculated using $3 \mathrm{D}$ finite element analysis by applying the current excitation of $1 \mathrm{~A}$. The SS and SP topology models are examined for cases. In the first case the coils are symmetrical i.e. the transmitter and receiver coils remain same size, while in the second case the coils are unsymmetrical i.e. the transmitter coil is bigger than the receiver coil. In section 2.4., the coils are integrated with circuit simulations to achieve the accurate analysis results at three different distances for both cases using SS and SP topology.

\subsection{Efficiency investigation and derivations of series-series (SS) topology model}

To derive the equations of efficiency, an equivalent circuit of SS topology model is shown in Figure 1(a). This research considers the fundamental component of voltage and current for simplicity.

Using Kirchhoff's Voltage Law (KVL), following equations can be derived using Figure 1 (a).

Int J Pow Elec \& Dri Syst Vol. 10, No. 4, Dec 2019 : 2157 - 2164 


$$
\begin{aligned}
& \mathrm{U}_{\mathrm{S}}=\mathrm{Z}_{1} \mathrm{I}_{\mathrm{S}}-\mathrm{j} \omega \mathrm{MI}_{\mathrm{L}} \\
& 0=-\mathrm{j} \omega \mathrm{MI}_{\mathrm{S}}+\mathrm{Z}_{2} \mathrm{I}_{\mathrm{L}}
\end{aligned}
$$

where $Z_{1}=R_{S}+\frac{1}{j \omega C_{1}}+R_{1}+j \omega L_{1}$ and $Z_{2}=j \omega L_{2}+R_{2}+\frac{1}{j \omega C_{2}}+R_{L}$

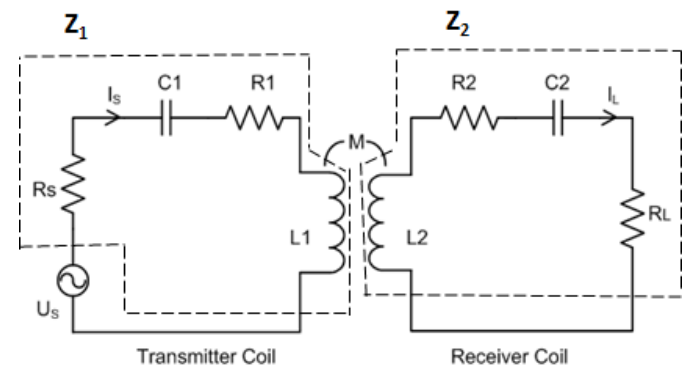

(a)

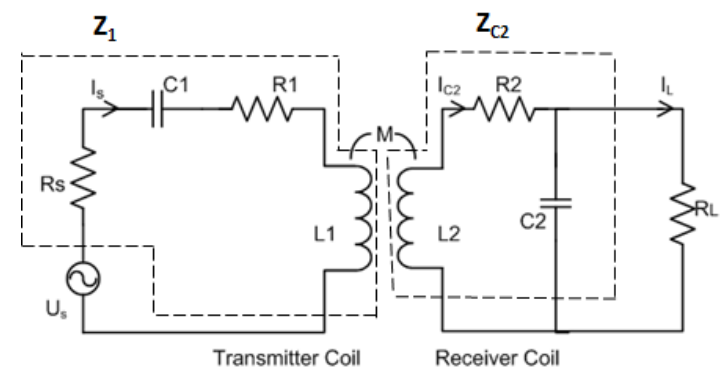

(b)

Figure 1. (a) Equivalent circuit of SS topology model (b) SP topology model

Figure 1 depicts the SS topology model, where $U_{S}$ is the source voltage applied on the transmitter resonator at resonance frequency $(\omega)$, and $Z_{1}$ and $Z_{2}$ are the impedances of transmitter and receiver side respectively. The mutual inductance $(M)$ between the transmitter and the receiver can be expressed in terms of coupling coefficient $k$ and coil inductances, which is given by,

$$
\mathrm{M}=\mathrm{k} \sqrt{\mathrm{L}_{1} \mathrm{~L}_{2}}
$$

Note that the higher coupling coefficient represents the small distance between the transmitter and receiver coil and vice versa. The currents flowing through the source side and the load are calculated by simplifying (1) and (2).

$$
I_{S}=\frac{Z_{2} U_{S}}{z_{1} Z_{2}+(\omega M)^{2}} \text { and } I_{L}=\frac{j \omega M U_{S}}{z_{1} Z_{2}+(\omega M)^{2}}
$$

Output power at given $R_{L}$ load and the efficiency $\eta$ can be expressed by (4),

$$
\eta_{\mathrm{ss}}=\frac{\mathrm{P}_{\text {out }_{\mathrm{SS}}}}{\mathrm{P}_{\mathrm{in}_{\mathrm{SS}}}} \times 100=\frac{\mathrm{I}_{\mathrm{L}}^{2} \mathrm{R}_{\mathrm{L}}}{\mathrm{U}_{\mathrm{S}} \mathrm{I}_{\mathrm{S}}}
$$

Additionally, in SS and SP topology models, the resonance occurs when the reactive impedance of the coil becomes zero and the reactance of the coil approaches to zero, then resonance frequencies of the transmitter $\omega_{1}$ and receiver $\omega_{2}$ become,

$$
\omega_{1,2}=\frac{1}{\sqrt{\mathrm{L}_{1,2} \mathrm{C}_{1,2}}}
$$

From the equations (3)-(5), it is concluded that the currents, voltages and efficiency can be calculated by using equivalent circuit method. According to Alanson et al. [9], there is a critical coupling parameter for distance known as the point of critical coupling $\left(\mathrm{K}_{\text {critical }}\right)$, apart from that point the system cannot operate a prescribed load at the maximum efficiency. In SS topology model, when the system is symmetrical, i.e. $\mathrm{R}_{1}=\mathrm{R}_{2}=\mathrm{R}_{\mathrm{X}}$ and $\mathrm{R}_{\mathrm{S}}=\mathrm{R}_{\mathrm{L}}=\mathrm{R}$; then $\mathrm{K}_{\text {critical }}$ is given by (6).

$$
\mathrm{K}_{\text {critical }}=\frac{\mathrm{R}+\mathrm{R}_{\mathrm{X}}}{\omega \mathrm{L}}
$$

As presented in (6), $K_{\text {critical }}$ is largely confined by $\omega L$ and the load resistance. For this reason, the series-series model is not capable of transferring power at large distance. From the above analytical equations, it can be concluded that series resonant model has their own pros and cons. The SS circuit model presents large value of maximum transfer efficiency owing to the less sensitivity for the parasitic resistance. 
But when the inductance is increased for realizing greater transfer distance; that will lead to decrease the efficiency because of larger parasitic resistance loss of large-sized coils. Moreover, the parasitic resistances $R 1$ and $R 2$ of the coil have the huge impact on the efficiency of the system. Small the parasitic resistance, higher the overall efficiency of system and vice versa. Additionally, the derivation of circuit parameters of SP compensation topology is presented in the section 2.2 .

\subsection{Efficiency investigation and derivations of series-parallel (SP) topology model}

The Series-Parallel (SP) topology can be defined as the series compensation from transmitter side and parallel compensation from receiver side as illustrated in Figure 1 (b). The following equations can be derived from Figure 1 (b), where $U_{S}$ is source voltage and $Z_{l}$ and $Z_{C 2}$ are the corresponding impedances from primary and secondary side. In this topology $C_{1}$ is connected in series from primary side and $C_{2}$ is connected in parallel from secondary side.

$$
\begin{aligned}
& \mathrm{U}_{S}=\mathrm{Z}_{1} \mathrm{I}_{\mathrm{S}}-\mathrm{j} \omega \mathrm{MI}_{\mathrm{C} 2} \\
& 0=-\mathrm{j} \omega \mathrm{MI}_{\mathrm{S}}+\mathrm{Z}_{C 2} \mathrm{I}_{\mathrm{C} 2}-\frac{1}{j \omega \mathrm{C}_{2}} \mathrm{I}_{\mathrm{L}} \\
& 0=-I_{C 2} \frac{1}{j \omega C_{2}}+\left(\frac{1}{j \omega C_{2}}+R_{L}\right) I_{L}
\end{aligned}
$$

where

$$
\mathrm{Z}_{1}=\mathrm{R}_{\mathrm{S}}+\frac{1}{\mathrm{j} \omega \mathrm{C}_{1}}+\mathrm{R}_{1}+\mathrm{j} \omega \mathrm{L}_{1} \quad \text { and } \quad \mathrm{Z}_{\mathrm{C} 2}=\mathrm{j} \omega \mathrm{L}_{2}+\mathrm{R}_{2}+\frac{1}{\mathrm{j} \omega \mathrm{C}_{2}}
$$

The currents $\mathrm{I}_{\mathrm{S}}, \mathrm{I}_{\mathrm{C} 2}$ and $\mathrm{I}_{\mathrm{L}}$ can be calculated by Cramer's rule.

$$
\begin{aligned}
& A=\left[\begin{array}{ccc}
Z_{1} & -j \omega M & 0 \\
-j \omega M & Z_{C 2} & -\frac{1}{j \omega C_{2}} \\
0 & -\frac{1}{j \omega C_{2}} & \frac{1}{j \omega C_{2}}+R_{L}
\end{array}\right] \\
& I_{S}=\frac{U_{S}}{A}\left[Z_{C 2}\left(\frac{1}{j \omega C_{2}}+R_{L}\right)+\frac{1}{\omega^{2} C_{2}{ }^{2}}\right] \\
& I_{C 2}=\frac{U_{S}}{A}\left[-j \omega M\left(\frac{1}{j \omega C_{2}}+R_{L}\right)\right] \\
& I_{L}=\frac{U_{S}}{A}\left(\frac{M}{C_{2}}\right) \\
& \eta_{S P}=\frac{P_{\text {out_sp }}}{P_{\text {in_sp }}} \times 100=\frac{I_{L}{ }^{2} R_{L}}{U_{S} I_{S}}
\end{aligned}
$$

The resonance frequency formula will remain the same for both SS and SP topology models as provided in (5). We can calculate the required capacitance value at our desired frequency using (5) in both cases. This resonance frequency formula is independence of coupling, because we must calculate resonance frequency for primary and secondary side separately. There is an impact of coupling coefficient $(k)$ on the resonance frequency. Due to variation in $k$ value, the resonating point of frequency may shift slightly, which is further discussed in section 3. The efficiency of SP compensation topology can be calculated using (14).

\subsection{Design of circular structures of symmetrical and unsymmetrical coils}

The spiral is a very popular structure in resonant wireless power transfer system due to its compact size and greatly confined electromagnetic field characteristics. An inclusive study of circular helix coils, planar spiral coils, and square helix coils was conducted in [25]. It was shown that the circular helix coils offer the best performance (e.g. the highest efficiency, the widest bandwidth, and the longest transfer distance) under optimal load whereas the planar spiral coils exhibit the worst performance among them. The optimal load can be defined as the load value, where the maximum efficiency is achievable. Another study regarding the shape of the coil was presented in [26]. It was found that circular geometries offer better coupling in perfect alignment while square types are better under misalignment between the coils.

Because of above mentioned advantages, circular coils are selected for this work. Two different cases are considered. In the first case, similar size coils are designed as illustrated in Figure 2 (a), while in the second case the transmitter coil has been kept bigger than the receiver coil as shown in Figure 2 (b). Second combination of coils can be suitable for biomedical applications. The dimensions of the big size coils and small size are given in Table 1. Big size coil in both cases has been kept similar. The self-inductance, mutual inductance and the coupling coefficients at three different distances are calculated using finite element method (FEM) simulations. The self-inductances of the coils, mutual inductances between the coils and coupling coefficient are analyzed at multiple distances and their results are provided in Table 2.

Int J Pow Elec \& Dri Syst Vol. 10, No. 4, Dec 2019 : 2157 - 2164 
Table 1. Parameters of bigger and small size coils

\begin{tabular}{cccc}
\hline Big Size Coils & Parameter Value $(\mathrm{mm})$ & Small Size Coil & Parameter Value $(\mathrm{mm})$ \\
\hline Polygon Radius & $2.5 \mathrm{~mm}$ & Polygon Radius & $2.5 \mathrm{~mm}$ \\
Start Helix Radius & $100 \mathrm{~mm}$ & Start Helix Radius & $20 \mathrm{~mm}$ \\
Radius Change & $7 \mathrm{~mm}$ & Radius Change & $7 \mathrm{~mm}$ \\
Pitch & $0 \mathrm{~mm}$ & Pitch & $0 \mathrm{~mm}$ \\
No. of Turns & 17 & No. of Turns & 10 \\
Diameter & $433 \mathrm{~mm}$ & Diameter & $176 \mathrm{~mm}$ \\
\hline
\end{tabular}

Table 2. Calculated values of distance vs coupling coefficient of symmetrical coils and unsymmetrical coils

\begin{tabular}{ccccccccc}
\hline $\begin{array}{c}\text { S. } \\
\text { No. }\end{array}$ & $\begin{array}{c}\text { Distance } \\
(\mathrm{mm})\end{array}$ & $\begin{array}{c}\text { Self- } \\
\text { Inductance } \\
\text { of Both } \\
\text { Symmetrical } \\
\text { Coils }(\mu \mathrm{H})\end{array}$ & $\begin{array}{c}\text { Mutual } \\
\text { Inductance } \\
(\mu \mathrm{H}) \\
\text { between } \\
\text { symmetrical } \\
\text { coils }\end{array}$ & $\begin{array}{c}\text { Coupling } \\
\text { Coefficient } \\
(\mathrm{k}) \text { between } \\
\text { symmetrical } \\
\text { coils }\end{array}$ & $\begin{array}{c}\text { Self- } \\
\text { Inductance } \\
\text { of Big Coil } \\
(\mu \mathrm{H})\end{array}$ & $\begin{array}{c}\text { Self- } \\
\text { Inductance } \\
\text { of Small } \\
\text { Coil }(\mu \mathrm{H})\end{array}$ & $\begin{array}{c}\text { Mutual } \\
\text { Inductance } \\
(\mu \mathrm{H}) \text { of } \\
\text { unsymmetrical } \\
\text { coils }\end{array}$ & $\begin{array}{c}\text { Coupling } \\
\text { Coefficient }(\mathrm{k}) \\
\text { between } \\
\text { unsymmetrical } \\
\text { coils }\end{array}$ \\
\hline 1 & 50 & 98.37 & 52.36 & 0.519 & 98.37 & 10.10 & 3.40 & 0.108 \\
2 & 100 & 98.37 & 28.95 & 0.286 & 98.37 & 10.10 & 1.95 & 0.062 \\
3 & 150 & 98.37 & 16.46 & 0.163 & 98.37 & 10.10 & 1.11 & 0.035 \\
\hline
\end{tabular}

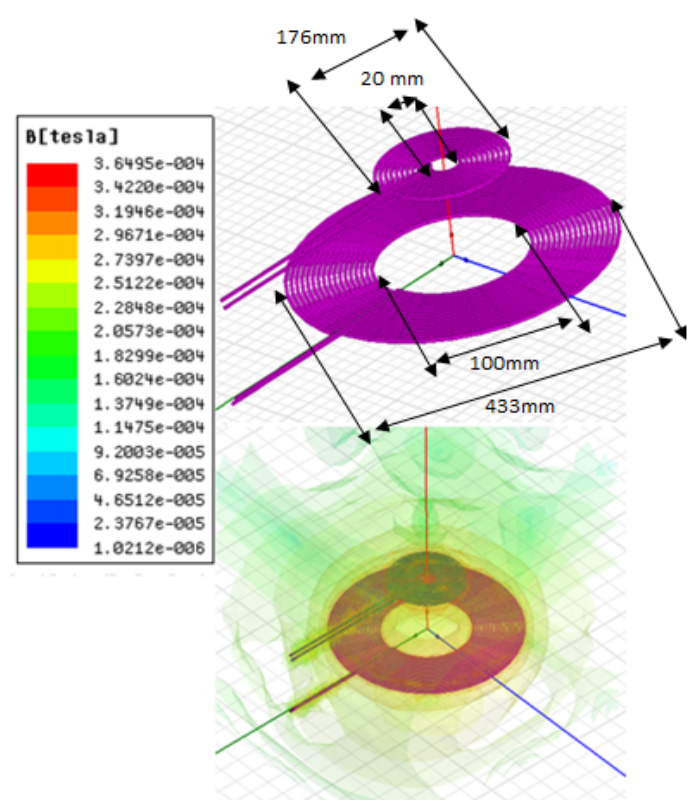

(a)

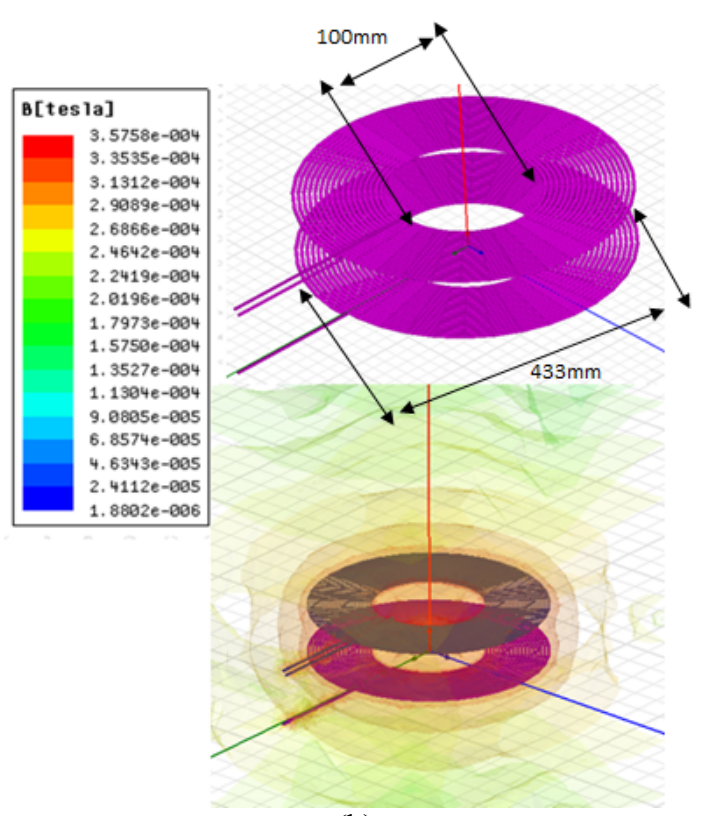

(b)

Figure 2. (a) Design of symmetrical coils and their magnetic field pattern (b) Design of Unsymmetrical coils and their magnetic field pattern

\subsection{Analysis of SS and SP Topology Models}

A schematic diagram of SS topology using symmetrical coils is shown in Figure 3. Instead of inductances $\mathrm{L}_{1}$ and $\mathrm{L}_{2}$, coil structures were integrated in circuit. SS and SP topology circuits are simulated for both symmetrical and unsymmetrical coils. The efficiency in terms of $\mathrm{P}_{\text {out }} / \mathrm{P}_{\text {in }}$ is calculated at three distances $50 \mathrm{~mm}, 100 \mathrm{~mm}$, and $150 \mathrm{~mm}$. The circuit and coil parameters used for simulations are given in Table 3. The inductance of coils is calculated using FEM analysis and other parameter values are extracted according to the given value of frequency and inductance. The resonance frequency is kept at $300 \mathrm{kHz}$. Analysis is performed for measuring power input and power output to find out the efficiency of WPT system at three different distances. 


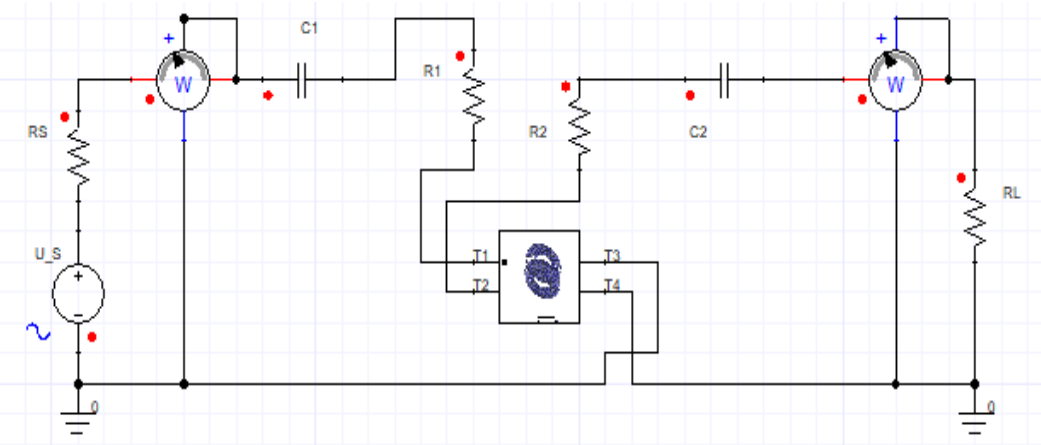

Figure 3. Simulation circuit of SS topology model using symmetrical coils

Table 3. Circuit Simulation parameters used for symmetrical and unsymmetrical coils

\begin{tabular}{cccc}
\hline Parameter Name of & Parameter Value of & Parameter Name of & Parameter Value of \\
Symmetrical Coils & Symmetrical Coils & Unsymmetrical Coils & Unsymmetrical Coils \\
\hline Us Amplitude & $10 \mathrm{~V}$ & Us Amplitude & $10 \mathrm{~V}$ \\
Frequency & $300 \mathrm{kHz}$ & $\mathrm{C}_{1}$ & $2.84 \mathrm{nF}$ \\
C1 \& C2 & $2.84 \mathrm{nF}$ & $\mathrm{C}_{2}$ & $28.4 \mathrm{nF}$ \\
Rs and R & $50 \Omega$ & $\mathrm{R}_{\mathrm{L}}$ and $\mathrm{R}_{\mathrm{L}}$ & $50 \Omega$ \\
L1 \& L2 & $98.37 \mu \mathrm{H}$ & $\mathrm{L}_{1}$ and L2 & $98.37 \mu \mathrm{H}$ and $10.10 \mu \mathrm{H}$ \\
$\mathrm{R}_{1} \& \mathrm{R}_{2}$ & $0.3 \Omega$ & $\mathrm{R}_{1} \& \mathrm{R}_{2}$ & $0.3 \Omega$ \\
\end{tabular}

\section{RESULTS AND ANALYSIS}

The simulation results for SS and SP topology models for three different distances using same size coils are given in Figure 5 (a). When we have simulated values of input power and output power, then the efficiencies can be calculated by (8) and (20) for SS and SP topology models. The efficiencies of SS compensation model at $50 \mathrm{~mm}, 100 \mathrm{~mm}$, and $150 \mathrm{~mm}$ are $98 \%, 97 \%$ and $93 \%$, respectively. For SP compensation model, the efficiencies at $50 \mathrm{~mm}, 100 \mathrm{~mm}$ and $150 \mathrm{~mm}$ are $72 \%, 38 \%$ and $53 \%$, respectively. Therefore, for the same size coils, it is obvious that SS compensation topology provides much better efficiency than SP topology. The simulation results for both topologies using different size coils are given in Figure 4. At the distance of $50 \mathrm{~mm}$, the efficiency is $73 \%$. While at $100 \mathrm{~mm}$, and $150 \mathrm{~mm}$, the efficiencies are $36 \%$ and $13 \%$, respectively. To analyze the efficiency of SP topology model using two different coils, the corresponding efficiencies at $50 \mathrm{~mm}, 100 \mathrm{~mm}$ and $150 \mathrm{~mm}$ are $92 \%, 89 \%$ and $71 \%$, respectively. Therefore, from the detailed investigation, it is concluded that when different size coils are used, SP compensation topology is promising choice, because it gives better efficiency than SS counterpart. Table 6 provides the efficiency calculations for both symmetrical (same size) and unsymmetrical (different size) coil simulation results. Because only resistive load is used, therefore only real component of power is included.

From Table 4, it is obvious that when symmetrical coils i.e. same size coils for transmitter and receiver are utilized then SS topology gives much higher efficiency at all three distances than SP topology. While by using unsymmetrical coils i.e. when transmitter coil is bigger than receiver coil, the SP topology gives much better efficiency than SS topology at all three distances. Therefore, these results are useful for deciding the desired topology according to specific design of coils, i.e. symmetrical or unsymmetrical

Table 4. Efficiency comparison of both topologies

\begin{tabular}{|c|c|c|c|c|c|c|c|c|}
\hline \multicolumn{3}{|c|}{ Distance $=50 \mathrm{~mm}$} & \multicolumn{3}{|c|}{ Distance $=100 \mathrm{~mm}$} & \multicolumn{3}{|c|}{ Distance $=150 \mathrm{~mm}$} \\
\hline Efficiency $(\%)$ & SS & SP & & SS & SP & & SS & SP \\
\hline Symmetrical Coils & 98 & 72 & Symmetrical Coils & 97 & 38 & Symmetrical Coils & 93 & 53 \\
\hline Unsymmetrical Coils & 73 & 92 & Unsymmetrical Coils & 36 & 89 & Unsymmetrical Coils & 13 & 71 \\
\hline
\end{tabular}




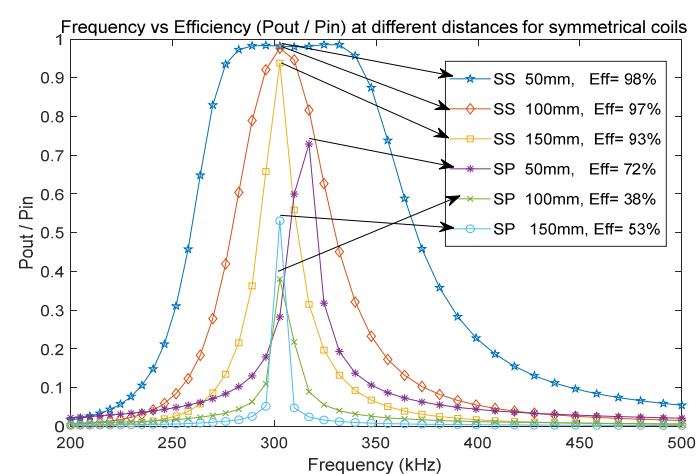

(a)

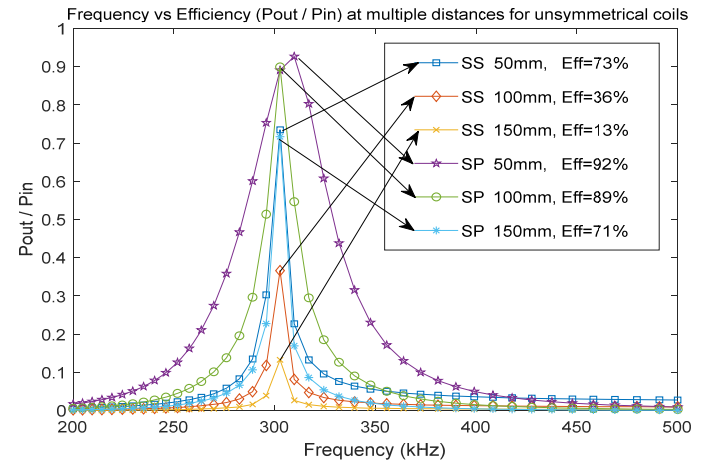

(b)

Figure 4. Efficiency result using SS and SP compensation (a) Symmetrical Coils (b) Unsymmetrical Coils

\section{CONCLUSION}

The modeling and investigation of two different circuit topologies for WPT system are carried out by circuit theory and simulations. The equations of power transfer efficiency in terms of circuit parameters and derivation of currents are presented. The effects of various coupling coefficients on the efficiency of the WPT system are also analyzed. It is confirmed that with increasing distance between transmitter and receiver coil, the coupling coefficient is decreasing rapidly. The frequency splitting phenomenon is not visible using both the topologies at all calculated distances. Therefore, it can be extracted that splitting frequency can be mitigated using SS and SP compensation topology with increasing coupling coefficient. The overall result shows that that SP topology model is suitable when Tx size bigger than Rx size. Because the SP topology gives much better efficiency than SS topology when two different size coils are utilized. SS topology is a good choice when two same size coils for transmitter and receiver are employed.

\section{ACKNOWLEDGEMENTS}

The authors would like to thank Universiti Teknologi PETRONAS for providing research fund to carry out this research.

\section{REFERENCES}

[1] N. Tesla, "Apparatus for transmitting electrical energy," ed: Google Patents, 1914.

[2] S. Y. R. Hui, W. Zhong, and C. K. Lee, "A critical review of recent progress in mid-range wireless power transfer," IEEE Transactions on Power Electronics, vol. 29, no. 9, pp. 4500-4511, 2014.

[3] D. Van Wageningen and T. Staring, "The Qi wireless power standard," in Power Electronics and Motion Control Conference (EPE/PEMC), 2010 14th International, 2010, pp. S15-25-S15-32: IEEE.

[4] S. D. Barman, A. W. Reza, N. Kumar, M. E. Karim, and A. B. Munir, "Wireless powering by magnetic resonant coupling: Recent trends in wireless power transfer system and its applications," Renewable and Sustainable Energy Reviews, vol. 51, pp. 1525-1552, 2015.

[5] B. L. Cannon, J. F. Hoburg, D. D. Stancil, and S. C. Goldstein, "Magnetic resonant coupling as a potential means for wireless power transfer to multiple small receivers," IEEE Transactions on Power Electronics, vol. 24, no. 7, pp. 1819-1825, 2009.

[6] D. Vilathgamuwa and J. Sampath, "Wireless Power Transfer (WPT) for Electric Vehicles (EVs)—Present and Future Trends," in Plug In Electric Vehicles in Smart Grids: Springer, 2015, pp. 33-60.

[7] C. E. Greene, D. W. Harrist, and M. T. McElhinny, "Powering cell phones and similar devices using RF energy harvesting," ed: Google Patents, 2007.

[8] A. Kurs, A. Karalis, R. Moffatt, J. D. Joannopoulos, P. Fisher, and M. Soljačić, "Wireless power transfer via strongly coupled magnetic resonances," science, vol. 317, no. 5834, pp. 83-86, 2007.

[9] A. P. Sample, D. T. Meyer, and J. R. Smith, "Analysis, experimental results, and range adaptation of magnetically coupled resonators for wireless power transfer," IEEE Transactions on Industrial Electronics, vol. 58, no. 2, pp. 544-554, 2011.

[10] J. Wang, S. Ho, W. Fu, and M. Sun, "Analytical design study of a novel witricity charger with lateral and angular misalignments for efficient wireless energy transmission," IEEE Transactions on Magnetics, vol. 47, no. 10, pp. 2616-2619, 2011.

[11] K. Fotopoulou and B. W. Flynn, "Wireless power transfer in loosely coupled links: Coil misalignment model," IEEE Transactions on Magnetics, vol. 47, no. 2, pp. 416-430, 2011. 
[12] S. Cheon, Y.-H. Kim, S.-Y. Kang, M. L. Lee, J.-M. Lee, and T. Zyung, "Circuit-model-based analysis of a wireless energy-transfer system via coupled magnetic resonances," IEEE Transactions on Industrial Electronics, vol. 58, no. 7, pp. 2906-2914, 2011.

[13] Y. Zhang, Z. Zhao, and K. Chen, "Frequency decrease analysis of resonant wireless power transfer," IEEE Transactions on Power Electronics, vol. 29, no. 3, pp. 1058-1063, 2014.

[14] R. Huang, B. Zhang, D. Qiu, and Y. Zhang, "Frequency splitting phenomena of magnetic resonant coupling wireless power transfer," IEEE Transactions on Magnetics, vol. 50, no. 11, pp. 1-4, 2014.

[15] W. Zhang, S.-C. Wong, K. T. Chi, and Q. J. I. T. o. P. E. Chen, "Analysis and comparison of secondary series-and parallel-compensated inductive power transfer systems operating for optimal efficiency and load-independent voltage-transfer ratio," vol. 29, no. 6, pp. 2979-2990, 2013.

[16] X. Qu, H. Han, S.-C. Wong, K. T. Chi, and W. J. I. T. o. p. e. Chen, "Hybrid IPT topologies with constant current or constant voltage output for battery charging applications," vol. 30, no. 11, pp. 6329-6337, 2015.

[17] R. Bosshard et al., "Modeling and \$leta \$-\$ \$alpha \$-Pareto Optimization of Inductive Power Transfer Coils for Electric Vehicles," vol. 3, no. 1, pp. 50-64, 2014.

[18] S. Liu, L. Chen, Y. Zhou, and T. J. J. I. j. o. e. Cui, "A general theory to analyse and design wireless power transfer based on impedance matching," vol. 101, no. 10, pp. 1375-1404, 2014.

[19] M. Rehman, Z. Baharudin, P. Nallagownden, B. J. I. J. o. E. E. Islam, and C. Science, "Modelling and EfficiencyAnalysis of Wireless Power Transfer using Magnetic Resonance Coupling," vol. 6, no. 3, pp. 563-571, 2017.

[20] M. Rehman, Z. Baharudin, P. Nallagownden, B. Islam, and M. U. J. I. Rehman, "Modeling and analysis of seriesseries and series-parallel combined topology for wireless power transfer using Multiple coupling coefficients," vol. 17, no. 11, p. 114, 2017.

[21] T. Linlin, Q. Hao, H. Xueliang, C. Weijie, and S. J. T. I. J. o. E. E. Wenhui, "A novel optimization means of transfer efficiency for resonance coupled wireless power transfer," vol. 11, no. 5, pp. 2747-2752, 2013.

[22] L. J. J. T. I. J. o. E. E. Yu, "Finite element analysis of a contactless power transformer with metamaterial," vol. 12, no. 1, pp. 678-684, 2014.

[23] D. Zhao, E. Ding, Y. Hu, and Z. J. T. I. J. o. E. E. Sun, "Design and Simulation of Multiple Coil Model for Wireless Power Transmission System," vol. 12, no. 6, pp. 4166-4177, 2014.

[24] C. K. H. C. K. Yahaya, S. F. S. Adnan, M. Kassim, R. A. Rahman, M. F. B. J. I. J. o. E. E. Rusdi, and C. Science, "Analysis of Wireless Power Transfer on the Inductive Coupling Resonant," vol. 12, no. 2, pp. 592-599, 2018.

[25] X. Shi et al., "Effects of coil shapes on wireless power transfer via magnetic resonance coupling," Journal of Electromagnetic Waves and Applications, vol. 28, no. 11, pp. 1316-1324, 2014.

[26] M. McDonough and B. Fahimi, "Comparison between circular and square coils for use in Wireless Power Transmission," 2014.

\section{BIOGRAPHIES OF AUTHORS}

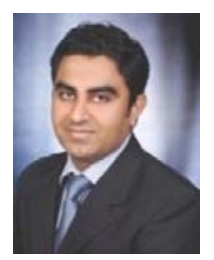

Masood Rehman received the Bachelor of Engineering Degree in Electrical Technology from Quaid-e-Awam University of Engineering, Science \& Technology (Q.U.E.S.T) Nawabshah, Pakistan in 2006. M.Sc. degree in Electrical \& Electronic Engineering, from Universität Duisburg-Essen, Germany, in 2013. He worked as an Electrical Engineer with SIEMENS, Pakistan and K-Electric Karachi, Pakistan. Currently, he is a studying PhD in Electrical and Electronics Engineering at Universiti Teknologi PETRONAS, Malaysia.

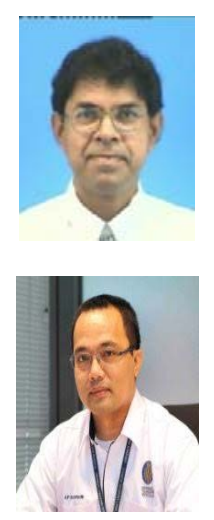

Perumal Nallagowanden is working as an associate professor in the Electrical \& Electronic Engineering Department in Universiti Teknologi PETRONAS. He received his Ph.D. from University of Wales, UK. His experience includes Polytecnic Ungku Omar, Conso Light Sdn Bhd and Universiti Teknologi PETRONAS. His special areas of interest are electrical power system, deregulated operation of power system, power quality and renewable energy (Tidal energy). He has published many research papers. He is a member of the Institution of Engineers Malaysia and is a professional engineer registered with the Board of Engineers Malaysia

Zuhairi Baharudin received his Ph.D. degree from Universiti Teknologi PETRONAS, Malaysia, in 2010. Currently, he is an Associate Professor in the department of Electrical and Electronics Engineering. He is very committed to his lectures and also actively doing research. He has published many papers in the area of power systems and communications technology. His research interests include forecasting, empirical modeling, renewable energy, power quality and harmonic studies, artificial intelligence applications and communication technologies.

Int J Pow Elec \& Dri Syst Vol. 10, No. 4, Dec 2019 : 2157 - 2164 